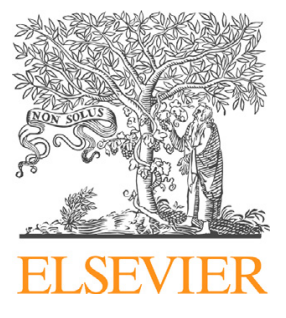

aDepartment of Urology, University Medical Center Utrecht, Utrecht, The Netherlands

bepartment of Pediatric Urology, University Children's Hospital UMC Utrecht and Academic Medical Center Amsterdam, Utrecht, The Netherlands

Correspondence to: S.P. Rynja, University Medical Center Utrecht, Heidelberglaan 100, Huispostnr. C 04.236, 3584 CX Utrecht, The Netherlands, Fax: +31302540532

sybrenrynja@hotmail.com (S.P. Rynja)

\section{Keywords}

Hypospadias; Androgen effect; Treatment outcome; Pediatrics; Testosterone

Received 22 April 2017 Accepted 19 September 2017 Available online 27 October 2017

\title{
Testosterone prior to hypospadias repair: Postoperative complication rates and long-term cosmetic results, penile length and body height
}

\author{
S.P. Rynja ${ }^{\text {a }}$, T.P.V.M. de Jong ${ }^{\text {a,b }}$, J.L.H.R. Bosch ${ }^{\text {a }}$, L.M.O. de Kort ${ }^{\text {a }}$
}

\section{Summary}

\section{Introduction}

The use of hormonal therapy was first described in 1971 before hypospadias surgery, and it has been debated ever since. The long-term outcomes after puberty of patients treated with pre-operative testosterone in childhood are lacking.

\section{Objectives}

Possible long-term effects of testosterone are often asked long-term outcomes regarding height, penile length and penile cosmesis in adult men after hypospadias surgery in childhood with and without pre-operative testosterone.

\section{Methods}

Adult men $(n=121)$ who underwent primary hypospadias repair in childhood were included. Pre-operative penile appearance, judged by a paediatric urologist, determined the use of pre-operative testosterone. Data on hypospadias characteristics, healing complications, surgical repair, and testosterone use were collected retrospectively. At adult age, stretched penile length and body height were measured, and penile cosmesis was evaluated using the Pediatric Penile Perception Score (PPPS).

\section{Results}

Postoperative complication rates in patients $(n=121)$ with and without testosterone were similar $(50 \%$ vs. $43 \%$; $P=0.54$ ). Sixty adult patients (50\%) with a median age of 19.8 years and follow-up time of 18.3 years were examined at the about in daily practice. The current study investigated the outpatient clinic at adult age. Of this group, testosterone was applied in 12/43 patients with distal, $3 / 6$ patients with midshaft, and $9 / 11$ patients with proximal hypospadias. Adult stretched penile length $(12.0 \mathrm{~cm}$ vs. $12.4 \mathrm{~cm} ; P=0.47)$ and adult height ( $180.1 \mathrm{~cm}$ vs. $179.0 \mathrm{~cm} P=0.65)$ showed no difference between patients with and without testosterone treatment. Penile cosmesis was (very) satisfactory in all PPPS domains, and showed no difference between the testosterone group and the non-testosterone group. Univariate and multivariate analysis was conducted to determine if the hypospadias type or pre-operative testosterone therapy had more influence on the long-term outcomes. None of the longterm outcomes were significantly associated with preoperative testosterone therapy on multivariate analysis.

\section{Discussion}

This was the first study reporting long-term outcomes of hypospadias patients after puberty who received preoperative hormonal therapy. Validated instruments were used as much as possible. Shortcomings of this study were the $50 \%$ response rate, the retrospective design, and the lack of objective inclusion criteria reported to indicate preoperative testosterone therapy.

\section{Conclusion}

This study suggested that the long-term results of patients receiving pre-operative testosterone treatment, who often had more challenging hypospadias, were similar to those who did not. However, a randomised controlled study is needed to confirm these results.
Summary Table Outcomes of multivariate regression analysis: impact of hypospadias severity versus pre-operative testosterone use on adult penile length and height, and cosmetic outcome measured by the Pediatric Penile Perception Score (PPPS).

\begin{tabular}{|c|c|c|c|c|c|c|}
\hline \multirow[t]{2}{*}{ Outcome variable } & \multicolumn{3}{|l|}{ Univariate analysis } & \multicolumn{3}{|c|}{ Multiple linear regression } \\
\hline & Predictor variable & Rho & $P$ & $\beta$ & $P$ & $\mathrm{Cl}(95 \%)$ \\
\hline \multirow[t]{2}{*}{ Penile length $(\mathrm{cm})$} & Hypospadias type & -0.48 & $<0.01$ & $-2.9^{*}$ & $<0.01$ & -4.4 to $1.4^{* *}$ \\
\hline & Testosterone use & -0.11 & 0.40 & 0.6 & 0.32 & -0.6 to 1.8 \\
\hline \multirow[t]{2}{*}{ Adult height $(\mathrm{cm})$} & Hypospadias type & -0.13 & 0.33 & & NS & \\
\hline & Testosterone use & -0.34 & 0.80 & & NS & \\
\hline \multirow[t]{2}{*}{ Outcome variable } & \multicolumn{3}{|l|}{ Univariate analysis } & \multicolumn{3}{|c|}{ Logistic regression } \\
\hline & Predictor variable & Rho & $P$ & OR & $P$ & $\mathrm{Cl}(95 \%)$ \\
\hline General aspect (PPPS) & Hypospadias type & 0.11 & 0.41 & & NS & \\
\hline Dissatisfied vs. satisfied & Testosterone & -0.07 & 0.60 & & NS & \\
\hline
\end{tabular}

Hypospadias type ranged from distal (1), midshaft (2) and proximal (3) hypospadias.

Testosterone use: no testosterone $(0)$ versus pre-operative testosterone treatment (1).

Pediatric Penile Perception Score (PPPS): (very) dissatisfied outcome (0) versus (very) satisfied outcome (1). Rho: Spearman's rank correlation.

OR: odds ratio.

*outcome for proximal hypospadias (1) compared to the remaining hypospadias subtypes (0). ${ }^{* *} R^{2}, 019$. 


\section{Introduction}

Hypospadias is the most common congenital penile abnormality; it occurs in 1 out of 250 newborn boys. Hormonal therapy prior to hypospadias repair was first described in 1971, but has since been debated [1]. Pre-operative hormonal stimulation is often applied in challenging hypospadias patients with a small penile or glanular size, or in patients with proximal hypospadias. It temporarily increases penile size and glanular diameter, and improves vascularization of the prepuce [2-6]. Shortage of glanular and penile tissue could hinder ventral closure of the neourethra in patients with a small penis or glans. Increasing this amount of tissue might facilitate reconstruction of an adequate-calibre neo-urethra resulting in low-pressure voiding. Improved quality of local tissue may also benefit wound healing and reduce complications. Thus, hypothetically, increasing the penile size with pre-operative testosterone might lead to improved outcomes in boys with challenging hypospadias.

Up to $90 \%$ of paediatric urologists use pre-operative testosterone treatment in selected cases to increase the penile size before hypospadias repair [7]. Long-term outcomes of pre-operative testosterone treatment are lacking - specifically regarding adult penile length, adult height and cosmetic outcomes - although this is frequently asked by parents in daily practice. Although this has not been studied in humans, there is some evidence of impaired adult penile length in rats receiving testosterone early in life [8]. Does testosterone also have a negative effect in humans? This study investigated these long-term results in patients with hypospadias who received pre-operative testosterone in childhood before primary hypospadias repair.

\section{Materials and methods}

\section{Study population}

The protocol for this retrospective study was approved by the local ethical committee (reference 09/038). Adult men operated for hypospadias in childhood between 1987 and 1993 were invited to participate. Patients with incorrect contact details and those referred for redo hypospadias repair were excluded. Participants provided informed consent and a physical examination was performed. Data were extracted from the medical files: hypospadias type defined by the Barcat classification (from perineal up to glanular), repair technique, presence of cryptorchidism or chordee, pre-operative testosterone treatment, and postoperative complication rates. Pre-operative testosterone treatment was either topical or intramuscular. At the time, topical cream with $5 \%$ Sustanon $^{\circledR}$ (a blend of testosterone propionate, phenylpropionate, isocaproate and decanoate) was applied twice a day during two periods of 14 days (separated by 1 week). Intramuscular therapy was 25 mg Sustanon ${ }^{\circledR}$ per week for $2-3$ weeks. A paediatric urologist indicated pre-operative hormonal treatment based on penile appearance, size of the prepuce, and penile length with a cut-off of $<45 \mathrm{~mm}$ to start treatment. Diameter of the glans was not measured. A
Mathieu or meatal advancement and glanuloplasty (MAGPI) technique was mostly performed in distal hypospadias patients; a vascularised preputial tube or onlay island flap technique was mostly used in patients with proximal hypospadias. If possible, reconstruction of the prepuce was offered [9]. Endpoints of this study were defined based on three aspects: adult stretched penile length, adult height, and adult penile cosmesis. Postoperative complications were analysed as the baseline parameter for the total patient group based on medical files; adult outcomes could only be assessed in those who participated and were examined at adult age.

\section{Complications}

Postoperative complications were categorised as wound healing-related complications (healing complications) and other complications. Urethrocutaneous fistulas, meatal stenosis, dehiscence, dehiscence of the prepuce, urethral stricture, and urethral diverticulum were scored as healing complications. Other complications were: urinary retention, UTI, residual chordee, cosmetic defects of the prepuce, a painful suture, or intra-urethral hair growth.

\section{Adult penile length}

The stretched penile length was measured in centimetres (cm) from the symphysis pubis to the glans tip with the penis maximally stretched while compressing the prepubic fat. Outcomes of the stretched penile length were compared to the pooled mean penile length reported by Veale of $13.24 \mathrm{~cm}$ (SD 1.89) and stratified in categories of -4 SD to +4 SD from this mean [10]. A micropenis was defined as a penile length -2.5 SD from the mean.

\section{Adult height}

The crown-heel height of patients was measured in centimetres. Outcomes were compared and stratified according to the national nomogram of adult height at age 21 years in The Netherlands, stating a mean height of 183.3 (SD 7.1) cm [11].

\section{Cosmetic results}

Cosmetic outcome was determined using the Pediatric Penile Perception Score (PPPS) [12]. The PPPS scores the aspect of the meatus, glans, penis and general penile appearance in a score from 0 points (very dissatisfied) to 3 points (very satisfied). An independent researcher, who was not the surgeon (SR), scored the cosmetic penile appearance. When in doubt, the PPPS score was discussed with a urologist (LdK, also not the surgeon).

\section{Statistical analysis}

Baseline characteristics of responders and non-responders were compared with the Mann-Whitney $U$ test for continuous data: age, follow-up duration, number of repairs, and timing of first repair. Discrete variables were analysed with Fisher's exact test: hypospadias subtype, repair technique and postoperative healing complications. Long-term 
outcomes were compared between responding patients with and without pre-operative testosterone treatment. Adult penile length and height outcomes were analysed with Students' $t$-test. Nomogram outcomes of adult height and penile length and PPPS outcomes were analysed using
Pearson's Chi-squared test. Results were considered statistically significant at a $P$-value $<0.05$.

The endpoints of this study - adult penile length, height and penile cosmesis - were analysed to identify which preoperative characteristic influenced the adult outcome

Table 1 Baseline characteristics of hypospadias patients: responders versus non-responders to invitation and baseline characteristics of hypospadias patients responding to the invitation with and without pre-operative testosterone treatment in childhood.

\begin{tabular}{|c|c|c|c|c|c|c|c|}
\hline & & \multicolumn{3}{|c|}{$\begin{array}{l}\text { Responders vs. non-responders to invitation } \\
\qquad(\mathrm{n}=121)\end{array}$} & \multicolumn{3}{|c|}{$\begin{array}{l}\text { Responding patients based } \\
\text { on testosterone use }(n=60)\end{array}$} \\
\hline & & $\begin{array}{c}\text { Yes } \\
\mathrm{n}=60\end{array}$ & $\begin{array}{c}\text { No } \\
\mathrm{n}=61\end{array}$ & $P$ & $\begin{array}{c}\text { Yes } \\
\mathrm{n}=24\end{array}$ & $\begin{array}{c}\text { No } \\
\mathrm{n}=36\end{array}$ & $P$ \\
\hline & & \multicolumn{2}{|c|}{ Median (IQR) } & U & \multicolumn{2}{|c|}{ Median (IQR) } & U \\
\hline \multicolumn{2}{|l|}{ Age first surgery (years) } & $1.3[0.9-3.3]$ & $1.6[1.0-3.9]$ & 0.43 & $1.2[0.9-1.6]$ & $1.8[0.9-3.9]$ & 0.07 \\
\hline \multicolumn{2}{|l|}{ Age at follow-up (years) } & $19.8[19.3-21.9]$ & $20.0[19.3-21.6]$ & 0.50 & $19.6[18.7-20.1]$ & $20.3[19.3-22.6]$ & $<0.05$ \\
\hline \multicolumn{2}{|l|}{$\begin{array}{l}\text { Follow-up since last } \\
\text { repair (years) }\end{array}$} & $18.3[17.4-19.0]$ & $18.2[17.4-19.0]$ & 0.91 & $18.0[17.1-18.6]$ & $18.4[17.7-19.3]$ & 0.09 \\
\hline \multicolumn{2}{|l|}{$\begin{array}{l}\text { Timing first complication } \\
\text { (months) }\end{array}$} & $7.3[5.0-43.8]$ & $8.2[5.1-27.7]$ & 0.52 & $4.5[1.2-7.0]$ & $10.0[6.5-31.2]$ & $<0.01$ \\
\hline \multicolumn{2}{|l|}{ Number of surgeries } & $\begin{array}{c}2.0[1.0-3.0] \\
n(\%)\end{array}$ & $\begin{array}{c}1.0[1.0-2.0] \\
n(\%)\end{array}$ & $\begin{array}{c}0.01 \\
X^{2}\end{array}$ & $\begin{array}{c}2.0[1.0-3.0] \\
n(\%)\end{array}$ & $\begin{array}{c}2.0[1.0-2.8] \\
n(\%)\end{array}$ & $\begin{array}{c}0.56 \\
X^{2}\end{array}$ \\
\hline \multicolumn{2}{|l|}{ Hypospadias type $^{\mathrm{b}}$} & & & 0.73 & & & $<0.01$ \\
\hline \multicolumn{2}{|l|}{ Distal } & $43 / 60(72)$ & $47 / 61(77)$ & & $12 / 24(50)$ & $31 / 36(86)$ & \\
\hline \multicolumn{2}{|l|}{ Midshaft } & $6 / 60(10)$ & $6 / 61(10)$ & & $3 / 24(13)$ & $3 / 36(8)$ & \\
\hline \multicolumn{2}{|l|}{ Proximal } & $11 / 60(18)$ & $8 / 61(13)$ & & $9 / 24(37)$ & $2 / 36(6)$ & \\
\hline \multicolumn{2}{|l|}{ Operation technique } & & & 0.06 & & & $<0.05$ \\
\hline \multicolumn{2}{|l|}{ Mathieu } & $32 / 60(53)$ & $34 / 61(56)$ & & $9 / 24(38)$ & $23 / 36(64)$ & \\
\hline \multicolumn{2}{|l|}{ MAGPI } & $6 / 60(10)$ & $16 / 61(26)$ & & $2 / 24(8)$ & $4 / 36(11)$ & \\
\hline \multicolumn{2}{|l|}{ Meatotomy } & $3 / 60(5)$ & - & & $2 / 24(8)$ & $1 / 36(2)$ & \\
\hline \multicolumn{2}{|l|}{ Duckett } & $12 / 60(20)$ & $9 / 61(15)$ & & $10 / 24(42)$ & $2 / 36(6)$ & \\
\hline \multicolumn{2}{|l|}{ Prepuce onlay } & $3 / 60(5)$ & $1 / 61(2)$ & & $1 / 24(4)$ & $2 / 36(6)$ & \\
\hline \multicolumn{2}{|l|}{ Other } & $4 / 60(7)$ & $1 / 61(2)$ & & - & $4 / 36(11)$ & \\
\hline \multicolumn{2}{|l|}{$\begin{array}{l}\text { Pre-operative hormonal } \\
\text { stimulation }\end{array}$} & $24 / 60(40)$ & $10 / 61(16)$ & $<0.01$ & N/A & N/A & \\
\hline \multirow{6}{*}{$\begin{array}{l}\text { Number of complications } \\
\text { per patient }\end{array}$} & 0 & $29 / 60(48)$ & $38 / 61(63)$ & 0.10 & $11 / 24(46)$ & $18 / 36(50)$ & 0.12 \\
\hline & 1 & $15 / 60(25)$ & $10 / 61(16)$ & & $5 / 24(21)$ & $10 / 36(28)$ & \\
\hline & 2 & $8 / 60(13)$ & $10 / 61(16)$ & & $3 / 24(12)$ & $5 / 36(14)$ & \\
\hline & 3 & $5 / 60(8)$ & $1 / 61(2)$ & & $2 / 24(8)$ & $3 / 36(8)$ & \\
\hline & 4 & $1 / 60(2)$ & $2 / 61(3)$ & & $1 / 24(4)$ & - & \\
\hline & $\geq 5$ & $2 / 60(4)$ & - & & $2 / 24(8)$ & - & \\
\hline \multicolumn{2}{|l|}{$\begin{array}{l}\text { Patients with urethral } \\
\text { fistula }\end{array}$} & $16 / 60(27)$ & $9 / 61(15)$ & 0.12 & $6 / 24(25)$ & $10 / 36(28)$ & 0.81 \\
\hline \multicolumn{2}{|l|}{ Patient with meatal stenosis } & $14 / / 60(23)$ & $9 / 61(15)$ & 0.26 & $7 / 24$ (29) & $7 / 36(19)$ & 0.54 \\
\hline \multicolumn{2}{|l|}{ Patients with dehiscence } & $2 / 60(4)$ & $4 / 61(7)$ & 0.68 & $1 / 24(4)$ & $1 / 36(3)$ & 1.00 \\
\hline \multicolumn{2}{|l|}{$\begin{array}{l}\text { Patients with dehiscence } \\
\text { of prepuce }\end{array}$} & $1 / 60(2)$ & $4 / 61(7)$ & 0.21 & $1 / 24(4)$ & $3 / 36(8)$ & 0.64 \\
\hline \multicolumn{2}{|l|}{$\begin{array}{l}\text { Patients with urethral } \\
\text { stricture }\end{array}$} & $5 / 60(8)$ & $7 / 61(11)$ & 0.76 & $3 / 24(12)$ & $2 / 36(6)$ & 0.38 \\
\hline \multicolumn{2}{|l|}{$\begin{array}{l}\text { Patients with urethral } \\
\text { diverticulum }\end{array}$} & $1 / 60(2)$ & $0 / 61(0)$ & 0.50 & $1 / 24(4)$ & $0 / 36(0)$ & 0.40 \\
\hline
\end{tabular}

$\mathrm{U}$ : Analysis performed by Mann-Whitney U test for continuous data.

$\mathrm{X}^{2}$ : Analysis performed by Fisher's exact test for discrete data.

IQR: Interquartile range.

N/A: not applicable.

Other: Glanular Approximation Procedure (1), 2-stage repair (1), no repair (1), unknown (1 responder, 1 non-responder).

Other in responding group: Glanular Approximation Procedure (1), 2-stage repair (1), no hypospadias repair (1), unknown (1).

a Complications: Urethrocutaneous fistulas, meatal stenosis, dehiscence, dehiscence of the prepuce, urethral strictures and urethral diverticulum.

b Based on Barcat classification. 
most: hypospadias subtype or pre-operative testosterone use. Univariate associations between these characteristics, baseline characteristics and the endpoints were analysed by Spearman's rank correlation. The type of correction technique was left out of the multivariate model, due to an expectedly high association with hypospadias subtype.

Subsequently, multivariate linear regression analysis was performed for continuous data: adult penile length and adult height. A binary logistic regression analysis was performed for categorical data of the general PPPS outcome (dissatisfied vs. satisfied). The pre-operative characteristics (hypospadias type: distal, midshaft or proximal) and preoperative testosterone use (yes, no) were included in every multivariate model, regardless of the $P$-value. All analyses were performed with the SPSS version 21.0.

\section{Results}

Of the 144 eligible patients, 121 with correct contact details and a primary reconstruction received an invitation. In total, 34 of $121(28 \%)$ patients received pre-operative testosterone. Testosterone was prescribed in 12 of the 19 patients with proximal hypospadias $(63 \%)$ compared to four of the 12 patients with midshaft hypospadias (33\%), and 18 of the 90 patients with distal hypospadias $(20 \% ; P<0.01)$. The indication for pre-operative testosterone was a short penile length in 25 patients, a small glanular aspect in one, and to increase the size of the prepuce in seven patients.
The indication was unknown in one patient. Patients with proximal hypospadias had more surgeries compared to patients with midshaft and distal hypospadias (median 3.0 vs. 1.5 and 1.0 repairs, respectively; $P<0.01$ ).

Of the 121 men, 60 (50\%) participated and 58 (48\%) underwent full physical examination. Table 1 presents the baseline characteristics of the responding group and the non-responding group. Responders were operated more often and were treated more frequently with testosterone compared to non-responders. Hypospadias subtype by Barcat classification and the applied surgical technique were strongly associated (univariate, rho $0.6, P<0.01$ ).

Baseline characteristics of the responders $(n=60)$ based on testosterone treatment are stated in Table 1. Testosterone was prescribed more often in patients with proximal hypospadias compared with distal hypospadias. No permanent side effects (pubic hair growth, behavioural or cognitive problems) of testosterone were reported in the medical files.

\section{Complications}

Complications occurred equally in the $34 / 121$ patients with pre-operative testosterone treatment compared to the 87 patients without testosterone treatment $(50 \%$ vs. $43 \%$, $P=0.54)$. The first complication after initial surgery occurred earlier in patients with testosterone compared to those without (median 5.3 months, range $1.4-11.9$ vs. 9.0 months, range $6.2-34.5, P<0.01$ ). Patients with proximal

Adult height (cm): $P=0.65$

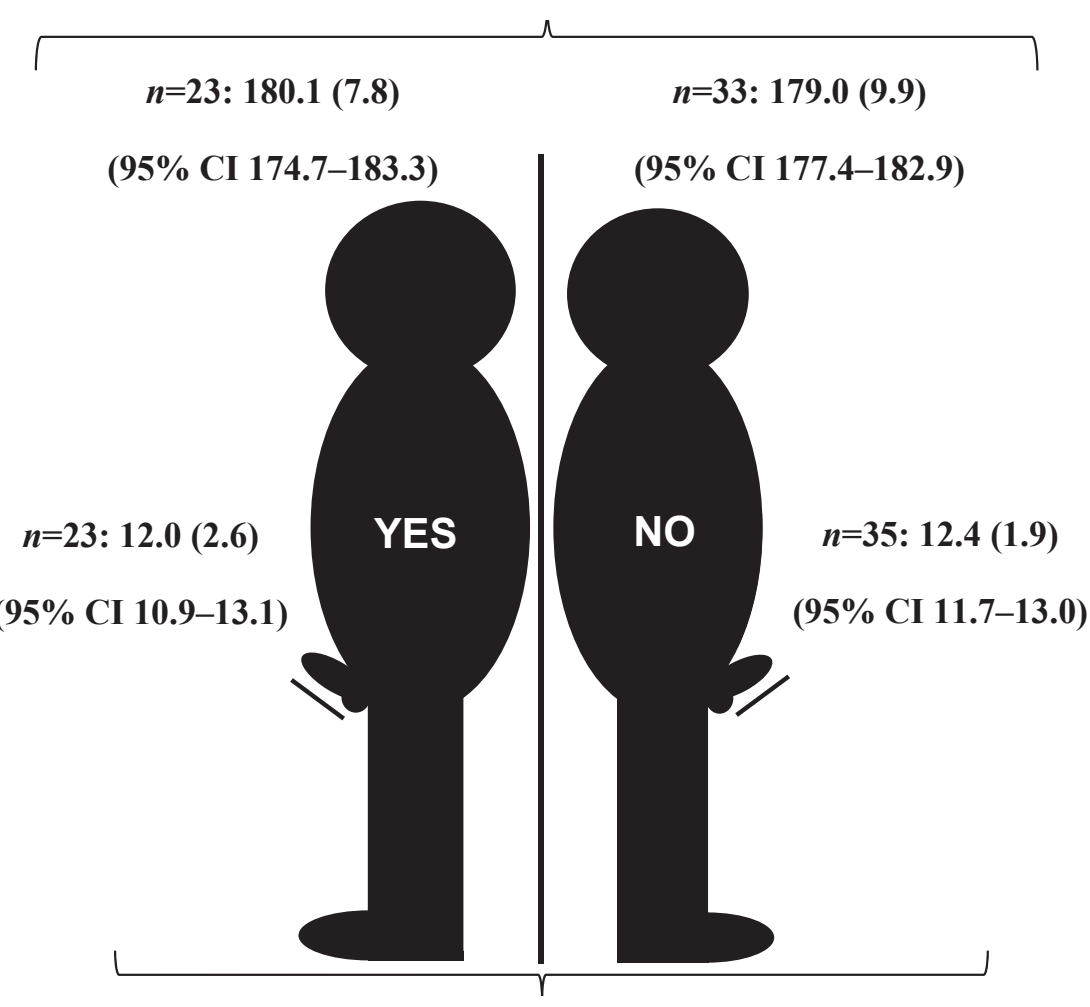

Stretched penile length (cm): $P=0.47$

Figure 1 Adult height $(\mathrm{cm})$ and adult stretched penile length $(\mathrm{cm})$ in hypospadias patients with (Yes) and without (No) preoperative hormonal stimulation. Analysis was performed with Student's $t$-test. 
hypospadias had healing complications more often than those with other hypospadias subtypes (median 3.0, range $2-3$ vs. 1.0 , range $1-2, P<0.01$ ). Patients with a Duckett repair had one or more complications compared to patients with a Mathieu repair $(8 / 12$ vs. $17 / 32 ; P<0.01)$.

\section{Adult penile length}

The adult stretched penile length was measured in 58/60 patients. Two distal hypospadias patients refused penile measurements, one had received pre-operative testosterone. Mean adult stretched penile length was comparable in patients with and without testosterone treatment $(12.4 \mathrm{~cm}$ vs. $12.0 \mathrm{~cm}, P=0.47$; Fig. 1$)$. Table 2 shows the data stratified into standard deviations (SDs) compared to Veale's nomogram [10]. Two patients with testosterone had a micropenis $(-2.5 \mathrm{SD})$ compared with one patient without testosterone $(P=0.55)$. Patients with proximal hypospadias $(n=11)$ had reduced adult penile length compared with 41 patients with distal hypospadias $(10.3 \mathrm{~cm}$ vs. $12.9 \mathrm{~cm}, P=0.01)$. Multivariate analysis, after correcting for testosterone treatment, confirmed these findings: the adult penile length was negatively associated with proximal hypospadias and not with testosterone (Table 3 ).

\section{Adult height}

The adult height is shown in Fig. 1; data were missing from four patients (one with testosterone, three without). Mean adult height was the same in patients with and without testosterone treatment $(180.1 \mathrm{~cm}$ vs. $179.8 \mathrm{~cm} ; P=0.65)$. Comparing outcomes to Schonbeck's nomogram showed no

Table 2 Outcomes of the Pediatric Penile Perception Score (PPPS) in hypospadias patients responding to the invitation for physical examination at the outpatient clinic at adulthood, and comparison of penile length and adult height compared to the nomograms of Veale [10] and Schonbeck [11].

\begin{tabular}{|c|c|c|c|}
\hline & $\begin{array}{l}\text { Testosterone } \\
n=24\end{array}$ & $\begin{array}{l}\text { No testosterone } \\
n=36\end{array}$ & \\
\hline & & & $P$ \\
\hline Meatal position (PPPS 1) & & & 0.38 \\
\hline Very dissatisfied & $1 / 24(4)$ & - & \\
\hline Dissatisfied & $5 / 24(21)$ & $4 / 36(11)$ & \\
\hline Satisfied & $14 / 24(58)$ & $27 / 36(75)$ & \\
\hline Very satisfied & $4 / 24(17)$ & $5 / 36(14)$ & \\
\hline Glandular aspect (PPPS 2) & & & 0.14 \\
\hline Very dissatisfied & - & - & \\
\hline Dissatisfied & $6 / 24(25)$ & $4 / 36(11)$ & \\
\hline Satisfied & $10 / 24(42)$ & $24 / 36(67)$ & \\
\hline Very satisfied & $8 / 24(33)$ & $8 / 36(22)$ & \\
\hline Penile aspect (PPPS 3) & & & 0.45 \\
\hline Very dissatisfied & $2 / 24(8)$ & $1 / 36(3)$ & \\
\hline Dissatisfied & $7 / 24(29)$ & $6 / 36(17)$ & \\
\hline Satisfied & $12 / 24(50)$ & $22 / 36(61)$ & \\
\hline Very satisfied & $3 / 24(13)$ & $7 / 36(19)$ & \\
\hline General cosmetic appearance & & & 0.73 \\
\hline Very dissatisfied & - & - & \\
\hline Dissatisfied & $3 / 24(13)$ & $3 / 36(8)$ & \\
\hline Satisfied & $18 / 24(75)$ & $30 / 36(84)$ & \\
\hline Very satisfied & $3 / 24(13)$ & $3 / 36(8)$ & \\
\hline $\begin{array}{l}\text { Stretched penile length compared to } \\
\text { nomogram of Veale (mean } 13.24 \mathrm{~cm} \text { ) }\end{array}$ & & & 0.27 \\
\hline$<9.2(>-2 \mathrm{SD})$ & $4 / 23(17)$ & $2 / 35(6)$ & \\
\hline $9.2-13.3(<-2 \mathrm{SD})$ & $11 / 23(48)$ & $22 / 35(63)$ & \\
\hline $13.5-17.6(<+2 \mathrm{SD})$ & $7 / 23(30)$ & $11 / 35(31)$ & \\
\hline$>17.6(>+2 \mathrm{SD})$ & $1 / 23(4)$ & - & \\
\hline $\begin{array}{l}\text { Adult height compared to nomogram } \\
\text { of Schonbeck (mean } 183.8 \mathrm{~cm} \text { ) }\end{array}$ & & & 0.94 \\
\hline$<169.6(>-2$ SD) & $2 / 23(9)$ & $3 / 33(9)$ & \\
\hline $169.6-183.7(<-2 \mathrm{SD})$ & $15 / 23(65)$ & $20 / 33(61)$ & \\
\hline $183.9-198.1(<+2$ SD $)$ & $6 / 23(26)$ & $10 / 33(30)$ & \\
\hline$>198.1(>+2 \mathrm{SD})$ & - & - & \\
\hline
\end{tabular}


Table 3 Outcomes of multivariate regression analysis: impact of hypospadias severity versus pre-operative testosterone use on adult penile length and height, and cosmetic outcome measured by the Pediatric Penile Perception Score (PPPS).

\begin{tabular}{|c|c|c|c|c|c|c|}
\hline \multirow[t]{2}{*}{ Outcome variable } & \multicolumn{3}{|l|}{ Univariate analysis } & \multicolumn{3}{|c|}{ Multiple linear regression } \\
\hline & Predictor variable & rho & $P$ & $\beta$ & $P$ & $\mathrm{Cl}(95 \%)$ \\
\hline \multirow{2}{*}{ Penile length $(\mathrm{cm})$} & Hypospadias type & -0.48 & $<0.01$ & $-2.9^{*}$ & $<0.01$ & -4.4 to $1.4^{* *}$ \\
\hline & Testosterone use & -0.11 & 0.40 & 0.6 & 0.32 & -0.6 to 1.8 \\
\hline \multirow[t]{2}{*}{ Adult height $(\mathrm{cm})$} & Hypospadias type & -0.13 & 0.33 & & NS & \\
\hline & Testosterone use & -0.34 & 0.80 & & NS & \\
\hline \multirow[t]{2}{*}{ Outcome variable } & \multicolumn{3}{|l|}{ Univariate analysis } & \multicolumn{3}{|c|}{ Logistic regression } \\
\hline & Predictor variable & rho & $P$ & OR & $P$ & $\mathrm{Cl}(95 \%)$ \\
\hline General aspect (PPPS) & Hypospadias type & 0.11 & 0.41 & & NS & \\
\hline Dissatisfied vs. satisfied & Testosterone & -0.07 & 0.60 & & NS & \\
\hline \multicolumn{7}{|c|}{$\begin{array}{l}\text { Hypospadias type ranged from distal (1), midshaft (2) and proximal (3) hypospadias. } \\
\text { Testosterone use: no testosterone (0) versus pre-operative testosterone treatment (1). } \\
\text { Pediatric Penile Perception Score (PPPS): (very) dissatisfied outcome (0) versus (very) satisfied outcome (1). } \\
\text { Rho: Spearman's rank correlation. } \\
\text { OR: odds ratio. } \\
{ }^{*} \text { outcome for proximal hypospadias (1) compared to the remaining hypospadias subtypes }(0) . \\
{ }^{* *} \mathrm{R}^{2}, 019 \text {. }\end{array}$} \\
\hline
\end{tabular}

differences between patients with and without testosterone $(P=0.85)$ (Table 2$)$. In multivariate analysis, adult height was not significantly associated with testosterone or hypospadias subtype (Table 3 ).

\section{Cosmesis}

The meatal position, glanular aspect and penile aspect were judged mainly 'satisfactory' in all patients, and outcomes were equal in patients with and without testosterone (Table 2). The general penile cosmetic aspect was (very) satisfactory in $88 \%$ of the patients with testosterone compared to $92 \%$ of the patients without (Table 2 ). The repair technique was not significantly associated with the general PPPS outcome (rho $0.23, P=0.08$ ). On both univariate and multivariate analysis, general penile appearance was not associated with testosterone use or hypospadias subtype (Table 3 ).

\section{Discussion}

In this study, hypospadias patients with pre-operative testosterone had similar adult penile length, adult height, and cosmetic outcomes to patients without testosterone treatment. It is believed that this is the first study to report long-term results after testosterone treatment in hypospadias patients using objective parameters and validated instruments.

The complication rate in the hypospadias patients with and without pre-operative testosterone was comparable; this was consistent with literature reviews [13-15]. Two recent randomised controlled trials reported contradicting outcomes: Asgari et al. reported a lower complication rate associated with pre-operative testosterone use, and Menon et al. concluded the opposite $[16,17]$. The current study did not find an increased complication rate, but neither did it find a clear benefit of testosterone $[3,18]$. The comparable complication rates are remarkable, since proximal hypospadias is a known risk factor for complications $[19,20]$. Hypothetically, the similar long-term outcomes plea for a beneficial effect of testosterone in challenging hypospadias cases, as was mentioned earlier by Wright [15]. The current study unfortunately lacked the power and methodology to prove this. The proportion of patients with at least one complication (44.6\%) was higher than the pooled complication rate mentioned in the literature (32.4\%) [15]. However, the current institution is a third-line referral centre for challenging hypospadias patients, as illustrated by a high prevalence of proximal hypospadias: $15.7 \%$ compared with $3.9 \%$ in the literature [21].

Overall, the adult stretched penile length was comparable in hypospadias patients with and without testosterone. Paediatric urologists tend to be sceptical about pre-pubertal testosterone use, which could potentially cause androgen receptor insensitivity at puberty and thus impair adult penile length, as has been reported in rats [8]. In the current analysis, the hypospadias subtype affected adult penile length rather than pre-operative testosterone. This information may help to inform parents of patients with proximal hypospadias to manage future expectations.

As testosterone treatment enhances bone maturation, pre-operative testosterone in childhood could result in a shorter adult body height $[22,23]$. The current results show that hypospadias patients in both groups were equally tall (i.e. no negative effect of hormonal treatment on adult height). Furthermore, adult height was similar to the average height reported in The Netherlands [11].

Penile cosmesis is an important long-term outcome, as a normal-appearing penis is one of the goals of hypospadias surgery. Cosmetic appearance was objectively assessed with the validated PPPS [12]. Outcomes of the PPPS were generally satisfactory in all domains. No cosmetic differences were seen between patients with and without testosterone. This finding is in contrast with the short-term 
cosmetic outcomes reported previously [3]. Long-term cosmetic outcomes are similar regardless of repair technique or hypospadias subtype; this may advocate testosterone use in challenging hypospadias cases.

The present study had some limitations. First, part of the data were collected retrospectively, implying disadvantages such as missing data or incomplete data: measurements of pre treatment penile and glanular sizes were barely documented in the medical files as well as (temporary) side effects of testosterone use. Indications for preoperative testosterone treatment were not based on objective measurements, but on the subjective judgement of the paediatric urologic surgeon. Thus, the data lacked standardised inclusion criteria for testosterone treatment, and outcomes have to be interpreted cautiously. Therefore, the data cannot answer which patient might benefit the most from pre-operative testosterone.

Another limitation was the low response rate to invitation $(50 \%)$, which may have made this study prone to bias. The responding patients had a higher number of surgical interventions and more often received pre-operative testosterone. As this was a selected patient group, longterm outcomes are not necessarily applicable to a more average group of hypospadias patients.

In the present study, different hormonal formulas were used (topical and intramuscular) and both methods are known to increase penile size [4]. The regimes varied considerably and pre-operative serum levels of testosterone were not determined. No conclusions could be drawn regarding which route of administration was preferred. Recent reviews have shown a paucity of reports dealing with the optimal dose, treatment regime, timing, and application method [13,15,24].

For future, a randomised study investigating the longterm effects would be the best possible method to study the pros and cons of testosterone use in hypospadias patients; however, this might be difficult to organise. The very least that can be done to improve hypospadias surgical results is standardised documentation of hypospadias patients. Pre-operative penile length and glans width should be documented before and after hormone treatment, as well as the indication for testosterone treatment. A glans width $<15 \mathrm{~mm}$ has been found to be a relatively good cutoff to determine testosterone therapy [25]. In order to be able to compare postoperative outcomes the following should be described and classified: hypospadias phenotype, defined intraoperatively, based on the level of the division of the corpus spongiosum; quality of the distal urethral plate and urethral groove; quality of penile skin; and degree of chordee $[26,27]$. In order to detect all long-term outcomes and complications, all hypospadias patients should be systematically followed until adulthood.

\section{Conclusion}

This study suggests that long-term adult height, penile length and penile cosmesis of patients who received preoperative testosterone treatment were the same as those not receiving testosterone. Hypospadias subtype appeared to be more determinative for the long-term outcome than testosterone treatment. As testosterone was more often administered in challenging cases, this suggests a beneficial effect of hormonal treatment. However, a randomised controlled trial is needed to analyze if pre-operative testosterone treatment benefits these challenging hypospadias patients.

\section{Conflict of interest/funding}

None.

\section{References}

[1] Immergut M, Boldus R, Yannone E, Bunge R, Flocks R. The local application of testosterone cream to the prepubertal phallus. J Urol 1971;105(6):905-6.

[2] Husmann DA. Microphallic hypospadias-the use of human chorionic gonadotropin and testosterone before surgical repair. J Urol 1999;162(4):1440-1.

[3] Kaya C, Bektic J, Radmayr C, Schwentner C, Bartsch G, Oswald J. The efficacy of dihydrotestosterone transdermal gel before primary hypospadias surgery: a prospective, controlled, randomized study. J Urol 2008;179(2):684-8. doi: S0022-5347(07)02600-6 [pii].

[4] Nerli RB, Koura A, Prabha V, Reddy M. Comparison of topical versus parenteral testosterone in children with microphallic hypospadias. Pediatr Surg Int 2009;25(1):57-9. https: //doi.org/10.1007/s00383-008-2278-6.

[5] Bastos AN, Oliveira LR, Ferrarez CE, de Figueiredo AA, Favorito LA, Bastos Netto JM. Structural study of prepuce in hypospadias-does topical treatment with testosterone produce alterations in prepuce vascularization? J Urol 2011;185(Suppl. 6): 2474-8. https://doi.org/10.1016/j.juro.2011.01.035.

[6] Gearhart JP, Linhard HR, Berkovitz GD, Jeffs RD, Brown TR. Androgen receptor levels and 5 alpha-reductase activities in preputial skin and chordee tissue of boys with isolated hypospadias. J Urol 1988;140(5 Pt 2):1243-6.

[7] Malik RD, Liu DB. Survey of pediatric urologists on the preoperative use of testosterone in the surgical correction of hypospadias. J Pediatr Urol 2014;10(5):840-3. https: //doi.org/10.1016/j.jpurol.2014.02.008.

[8] MCMahon DR, Kramer SA, Husmann DA. Micropenis: does early treatment with testosterone do more harm than good? J Urol 1995;154(2 Pt 2):825-9. doi: S0022-5347(01)67175-1 [pii].

[9] de Jong TP, Boemers TM. Improved Mathieu repair for coronal and distal shaft hypospadias with moderate chordee. Br J Urol 1993;72(6):972-4.

[10] Veale D, Miles S, Bramley S, Muir G, Hodsoll J. Am I normal? A systematic review and construction of nomograms for flaccid and erect penis length and circumference in up to 15,521 men. BJU Int 2015;115(6):978-86. https://doi.org/10.1111/ bju.13010.

[11] Schonbeck Y, Talma H, van Dommelen P, et al. The world's tallest nation has stopped growing taller: the height of Dutch children from 1955 to 2009. Pediatr Res 2013;73(3):371-7. https://doi.org/10.1038/pr.2012.189.

[12] Weber DM, Schonbucher VB, Landolt MA, Gobet R. The pediatric penile perception score: an instrument for patient selfassessment and surgeon evaluation after hypospadias repair. J Urol 2008;180(3):1080-4. https://doi.org/10.1016/j.juro. 2008.05.060. discussion 1084 .

[13] Wong NC, Braga LH. The influence of pre-operative hormonal stimulation on hypospadias repair. Front Pediatr 2015;3:31. https://doi.org/10.3389/fped.2015.00031.

[14] Chao M, Zhang Y, Liang C. Impact of pre-operative hormonal stimulation on post-operative complication rates after 
hypospadias repair: a meta-analysis. Minerva Urol Nefrol 2017 Jun;69(3):253-61.

[15] Wright I, Cole E, Farrokhyar F, Pemberton J, Lorenzo AJ, Braga LH. Effect of preoperative hormonal stimulation on postoperative complication rates after proximal hypospadias repair: a systematic review. J Urol 2013;190(2):652-9. https: //doi.org/10.1016/j.juro.2013.02.3234.

[16] Menon P, Rao KL, Handu A, Balan L, Kakkar N. Outcome of urethroplasty after parenteral testosterone in children with distal hypospadias. J Pediatr Urol 2017 Jun;13(3):292.e1-7.

[17] Asgari SA, Safarinejad MR, Poorreza F, Safaei Asl A, Mansour Ghanaie M, Shahab E. The effect of parenteral testosterone administration prior to hypospadias surgery: a prospective, randomized and controlled study. J Pediatr Urol 2015;11(3): 143. https://doi.org/10.1016/j.jpurol.2014.12.014. e1-143.e6.

[18] Chen C, Gong CX, Zhang WP. Effects of oral testosterone undecanoate treatment for severe hypospadias. Int Urol Nephrol 2015; 47(6):875-80. https://doi.org/10.1007/s11255-015-0972-6.

[19] Spinoit AF, Poelaert F, Van Praet C, Groen LA, Van Laecke E, Hoebeke P. Grade of hypospadias is the only factor predicting for re-intervention after primary hypospadias repair: a multivariate analysis from a cohort of 474 patients. J Pediatr Urol 2015;11(2): 70. https://doi.org/10.1016/j.jpurol.2014.11.014. e1-70.e6.

[20] Bush NC, Villanueva C, Snodgrass W. Glans size is an independent risk factor for urethroplasty complications after hypospadias repair. J Pediatr Urol 2015;11(6):355. https: //doi.org/10.1016/j.jpurol.2015.05.029. e1-355.e5.
[21] Bergman JE, Loane $M$, Vrijheid $M$, et al. Epidemiology of hypospadias in europe: a registry-based study. World $\mathrm{J}$ Urol 2015;33(12):2159-67. https://doi.org/10.1007/s00345-0151507-6.

[22] Blethen SL, Gaines S, Weldon V. Comparison of predicted and adult heights in short boys: effect of androgen therapy. Pediatr Res 1984;18(5):467-9.

[23] Mayo A, Macintyre H, Wallace AM, Ahmed SF. Transdermal testosterone application: pharmacokinetics and effects on pubertal status, short-term growth, and bone turnover. J Clin Endocrinol Metab 2004;89(2):681-7. https://doi.org/10. 1210/jc.2003-031086.

[24] Netto JM, Ferrarez CE, Schindler Leal AA, Tucci Jr S, Gomes CA, Barroso Jr U. Hormone therapy in hypospadias surgery: a systematic review. J Pediatr Urol 2013;9(6 Pt B): 971-9. https://doi.org/10.1016/j.jpurol.2013.03.009.

[25] Snodgrass WT, Villanueva C, Granberg C, Bush NC. Objective use of testosterone reveals androgen insensitivity in patients with proximal hypospadias. J Pediatr Urol 2013. https: //doi.org/10.1016/j.jpurol.2013.07.006.

[26] Mouriquand PD, Gorduza DB, Noche ME, Targnion A. Long-term outcome of hypospadias surgery: current dilemmas. Curr Opin Urol 2011;21(6):465-9. https://doi.org/10.1097/MOU.0b013 e32834a6da3.

[27] Malone P. Commentary to "A standardized classification of hypospadias". J Pediatr Urol 2012;8(4):415. https://doi.org/ 10.1016/j.jpurol.2011.08.006. 